Article

\title{
Preparation and Properties of Biobased, Cationic, Waterborne Polyurethanes Dispersions from Castor Oil and Poly (Caprolactone) Diol
}

\author{
Ying $\mathrm{Li}^{1}$, Sichong Chen ${ }^{2}$, Jun Shen ${ }^{1, *}$, Siqi Zhang ${ }^{1}$, Ming Liu ${ }^{1}$, Ruixue $\operatorname{Lv}^{1}$ and Wang Xu ${ }^{1}$ \\ 1 Key Laboratory of Biobased Material Science \& Technology, Ministry of Education, Northeast Forestry \\ University, Harbin 100040, China; tian18386790@126.com (Y.L.); 987137216@nefu.edu.cn (S.Z.); \\ liuming1997@nefu.edu.cn (M.L.); 2016224287@nefu.edu.cn (R.L.); xuwang@nefu.edu.cn (W.X.) \\ 2 College of Chemistry, Sichuan University, Chengdu 610064, China; chensichong@scu.edu.cn \\ * Correspondence: shenjunr@126.com
}

check for updates

Citation: Li, Y.; Chen, S.; Shen, J.; Zhang, S.; Liu, M.; Lv, R.; Xu, W. Preparation and Properties of Biobased, Cationic, Waterborne Polyurethanes Dispersions from Castor Oil and Poly (Caprolactone) Diol. Appl. Sci. 2021, 11, 4784 https://doi.org/10.3390/app11114784

Academic Editor:

Alessandro Pegoretti

Received: 14 April 2021

Accepted: 19 May 2021

Published: 23 May 2021

Publisher's Note: MDPI stays neutral with regard to jurisdictional claims in published maps and institutional affiliations.

Copyright: (c) 2021 by the authors. Licensee MDPI, Basel, Switzerland. This article is an open access article distributed under the terms and conditions of the Creative Commons Attribution (CC BY) license (https:// creativecommons.org/licenses/by/ $4.0 /$ )

\begin{abstract}
Biobased cationic waterborne polyurethanes (WPUs) were prepared using isophorone diisocyanate (IPDI), N-methyl diethanolamine (N-MDEA), polycaprolactone (PCL) diol, hydrochlotic acid $(\mathrm{HCl})$, and 1,4-butanediol (BDO). To improve the mechanical performance and adhesive strength of the waterborne polyurethane films, different amounts of castor oil (CO) acting as a cross-linking agent were incorporated in the polyurethane structure. The structures of the waterborne polyurethanes were assessed by Fourier-transform infrared spectroscopy (FTIR). The combination of CO had a positive effect on the dispersion and stability properties of WPUs. WPUs containing higher content of CO demonstrated a remarkable enhancement in homogeneity among particles. The stable aqueous dispersion was obtained even when N-MDEA loading was as low as $3.2 \mathrm{wt} \%$; a bonus of this low hydrophilic moiety was the excellent adhesive strength, whose T-peel strength could reach up to $36.8 \mathrm{~N} / 25 \mathrm{~mm}$, about 114\% higher than that of WPU $(17.2 \mathrm{~N} / 25 \mathrm{~mm})$ without any CO content. The elongation at break of $\mathrm{CO}_{7.40 \%}$-WPU was $391 \%$. In addition, the fracture mechanism of the waterborne polyurethane films transformed from the brittle failure to the ductile fracture. The experiment results showed the CO-modified WPUs displayed excellent film-forming property, flexibility, and adhesion, which can be employed for constructing the eco-friendly, biodegradable, cationic, waterborne polyurethanes.
\end{abstract}

Keywords: cationic; waterborne polyurethanes; biodegradable; castor oil; cross-linking agent; polycaprolactone diol

\section{Introduction}

Polyurethane (PU) has received great attention in a variety of applications (e.g., adhesive materials, textile, glove, paints, wood finishing, etc.), owing to its excellent mechanical and physical properties [1,2]. Because of the worldwide restriction on volatile organic chemicals (VOCs), there is a tendency to replace conventional, organic, solvent-based polyurethanes by waterborne polyurethanes (WPUs) [3-6]. The utilization of water, rather than organic solvent, as a dispersion medium may avoid unnecessary environmental pollution as it is pollutant-free and odorless, which is in compliance with the requirements of environmental protection regulations.

To be dispersible in water, WPUs should contain ionic or nonionic hydrophilic segments in their structure. According to the types of ionic groups incorporated, the dispersion can be categorized as cationic, anionic, or zwitterionic. As an important category of WPUs, cationic WPUs have an extremely high adhesion capacity to different ionic substrates, particularly for anionic substrates (e.g., glass, leather, etc.) [7-10]. Thus, cationic WPUs can be utilized as an important adhesive or coagulant [11-13]. N-Methyl diethanolamine has been widely employed as a cationic hydrophilic group in WPU dispersions [8,12]. 
Incorporation of strong polar cationic groups into hard segments of linear PUs considerably improves polarity, resulting in cationic WPUs with improved adhesion strength on anionic substrate $[7,11]$. However, most of the WPUs molecules have linear structure and some properties of WPU still need to be improved further, such as thermal stability, water resistance, brittleness, etc. [14,15]. To improve these properties, great effort has been made to accelerate the development of WPUs [16-19].

Polymers from renewable resources have been widely studied over the past decades ref. [20-23], mainly due to their environmental impacts and finite petroleum resources. Biobased polyurethane (BPU) has received considerable attention as an eco-friendly material for reducing fossil oil depletion, environmental pollution, carbon dioxide emission, and global warming [24-26]. Plant oils derived from castor, sunflower, palm, canola, and soybean have a great potential to replace petroleum for the production of polyols (a raw material used to synthesize PUs) $[27,28]$. Among them, castor oil (CO) has been widely applied due to its environmental friendliness, large availability, biodegradability, cost-effectiveness, and easily extractable from castor seeds. CO consists of $88 \%$ ricinoleic acid and has an average hydroxyl functionality of 2.7. Therefore, $\mathrm{CO}$ can be directly employed as polyols to synthesize PUs $[29,30]$. However, CO does not have the rigidity and strength properties required for structural applications because of its low functionality and relatively lower reactivity of secondary hydroxyl groups. Low hydroxyl number of $\mathrm{CO}$ also leads to a poor performance of the resulting polymer materials [31], which hindered their use in many applications. In addition, the soft-segment diols, hard-segment diisocyanates, and chain extenders lead to environmental pollution owing to their low biodegradability. With the rising awareness about the environmental challenges associated with the difficult-to-decompose plastics, the application of degradable materials has received a widespread attention. PCL is a hydrophobic aliphatic polyester that can be generated from petroleum or renewable resources (e.g., polysaccharides) via chemical synthesis [32]. It is often considered as a green polymer on account of its biocompatibility and biodegradability by microorganisms $[33,34]$. Besides, PCL is an easily processable and completely biodegradable synthetic material that can be used with conventional melt processing equipment [35]. Indeed, PCL has been applied in a wide range of fields such as food packaging and biomedical devices $[33,36,37]$. As an important class of polymers, PCL-WPUs can be employed in many applications including adhesives, controlled drug release systems, medical devices, ink, and biodegradable packaging [38-40]. However, it is worth mentioning that PCL is a linear and semi-crystalline aliphatic polyester and the production of PCL films is hampered by its low mechanical strength, low melting temperature, and thermal stability [41].

It has been reported that the crystallization behavior of semicrystalline polymer plays an essential role in regulating its mechanical properties, and the addition of second materials can influence its crystallinity. [42] Taking these antecedents into account, this study utilized biodegradable segments (PCL) as PU soft segments to enhance its performance for environmental protection, and imported $\mathrm{CO}$ to produce emulsions. Using $\mathrm{CO}$ as an addition of second material improves the mechanical properties, wettability, water resistance, and adhesive strength of PCL-WPUs. To the best of our knowledge, biodegradable, castor-oil-based, cationic PCL-WPUs have not been previously reported in the open literature. Castor oil with an average hydroxyl functionality of 2.7 and a relatively higher molecular weight than 1,4-BDO acted as a cross-linking agent and chain extender instead of part of BDO to prepare reticular polyurethane. The particle size of the WPU emulsion was subsequently assessed. Furthermore, structural and surface characterizations of WPUs material were studied to examine the influence of $\mathrm{CO}$ on the targeted properties of WPUs.

\section{Materials and Methods}

\subsection{Chemicals}

Hydrochloric acid $(\mathrm{HCl})$ (AR, Sinopharm, Beijing, China), isophorone diisocyanate (IPDI) (98\%, Aladdin, Shanghai, China,), dibutyltin dilaurate (DBTDL) (95\%, Aladdin, 
Shanghai, China), N-methyl diethanolamine (N-MEDA) (AR, Aladdin, Shanghai, China),1,4butanediol (BDO) (AR, Sinopharm, Beijing, China), castor oil (USP, Aladdin, Shanghai, China), and butanone (AR, Sinopharm, Beijing, China) were used as received. Poly (caprolactone) diol 2000 (AR, Sinopharm, Beijing, China) and PCL-polyol were dehydrated under vacuum at $95^{\circ} \mathrm{C}$ for $3 \mathrm{~h}$ before use.

\subsection{Synthesis of WPU}

The WPUs were synthesized based on the modified acetone process [43], where butanone was used as a solvent (Scheme 1). IPDI and polyols were charged in the reactor, along with DBTDL catalyst under $\mathrm{N}_{2}$ atmosphere. The reaction was proceeded at $75{ }^{\circ} \mathrm{C}$ until the theoretical NCO content of the prepolymers was reached, as determined by the di-n-butylamine titration method. Subsequently, N-MDEA was added and the reaction was proceeded for $1 \mathrm{~h}$ to attain the backbone hydrophilicity at $30^{\circ} \mathrm{C}$. Afterwards, $\mathrm{CO}$ was added, and the reaction was continued for $2 \mathrm{~h}$ at $78{ }^{\circ} \mathrm{C}$. Finally, BDO was added to the reaction mixture, followed by the continuation of the reaction for $2 \mathrm{~h}$ at $78^{\circ} \mathrm{C}$. Subsequently, the reaction mixture was cooled to $25^{\circ} \mathrm{C}$ and butanone $(20 \mathrm{wt} \%)$ was added to reduce its viscosity. The neutralization reaction proceeded at the same temperature for $30 \mathrm{~min}$. Following this, distilled water was added to the reactor, and contents were stirred at $600 \mathrm{rpm}$ for $60 \mathrm{~min}$ and $300 \mathrm{rpm}$ for another $60 \mathrm{~min}$. Finally, butanone was removed by using a rotary evaporator at $50{ }^{\circ} \mathrm{C}$ under vacuum to obtain the WPU material. The composition and properties of WPUs are listed in Table 1, and the reaction schematic is illustrated in Scheme 1.

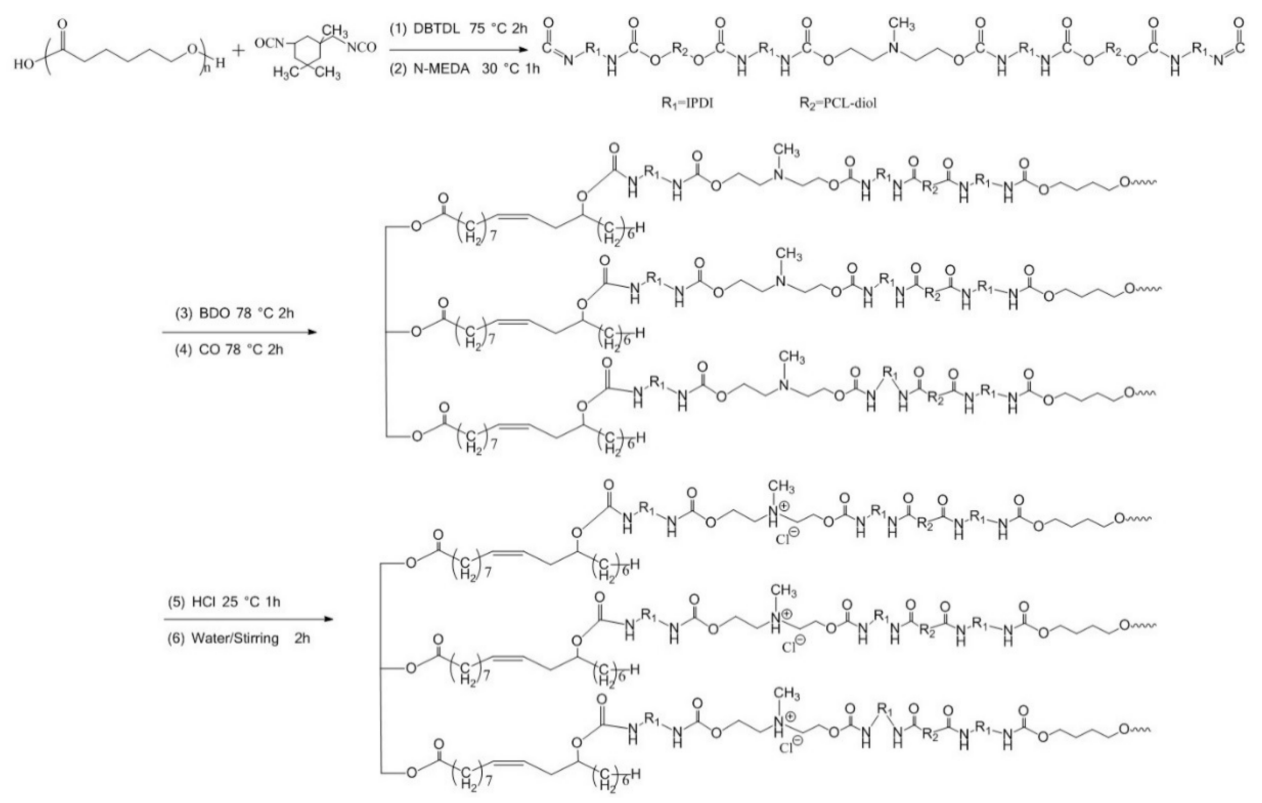

Scheme 1. Schematic of the reaction to synthesize WPU.

Table 1. Feeding composition and properties of WPUs.

\begin{tabular}{|c|c|c|c|c|c|c|c|}
\hline Samples & $\begin{array}{l}\text { PCL-OH } \\
\text { (Molar) }\end{array}$ & $\begin{array}{c}\text { CO } \\
\text { (Molar) }\end{array}$ & $\begin{array}{c}\text { MDEA } \\
(w t \%)\end{array}$ & $\begin{array}{c}\text { Hard } \\
\text { Segment }(w t \%)\end{array}$ & $\mathrm{CO}(w t \%)$ & $\begin{array}{l}\text { T-Peel Strength } \\
\text { (N/25 mm) }\end{array}$ & $\begin{array}{c}\text { Zeta } \\
\text { Poterntial } \\
(\mathrm{mV})\end{array}$ \\
\hline $\mathrm{CO}_{0 \%}-\mathrm{WPU}$ & 1 & 0 & 3.8 & 37.5 & 0 & 17.2 & 39 \\
\hline $\mathrm{CO}_{2.50 \%}-\mathrm{WPU}$ & 1 & 0.095 & 3.3 & 38.9 & 2.5 & 23.4 & 45 \\
\hline $\mathrm{CO}_{5.04 \%}-\mathrm{WPU}$ & 1 & 0.190 & 3.2 & 40.3 & 5.0 & 29.5 & 50 \\
\hline $\mathrm{CO}_{7.40 \%}-\mathrm{WPU}$ & 1 & 0.285 & 3.2 & 41.6 & 7.4 & 36.8 & 54 \\
\hline $\mathrm{CO}_{9.66 \%}-\mathrm{WPU}$ & 1 & 0.380 & 3.1 & 42.8 & 9.7 & 26.8 & 55 \\
\hline
\end{tabular}




\subsection{Characterization}

The free-standing WPU films were prepared according to the following method: The WPU dispersions were poured in the Teflon molds for drying at room temperature for 7 days followed by drying for $24 \mathrm{~h}$ in a vacuum oven at $40^{\circ} \mathrm{C}$. Subsequently, the films were stored in a desiccator to avoid moisture uptake.

The FT-IR analysis was carried out on Bruker TENSOR-27 spectrometer at a resolution of $4 \mathrm{~cm}^{-1}$ in the wavenumber range of $4000-400 \mathrm{~cm}^{-1}$, For this purpose, the acetone solutions of the specimens were cast on the $\mathrm{KBr}$ pellets.

The average particle size and particle size distribution (PSD) of the WPUs were measured using an ALV CGS-3 light scattering spectrometer equipped with an ALV-5000 multi-tau digital time correlator and a He-Ne laser $(\lambda=632 \mathrm{~nm})$. The WPU dispersions were first diluted in deionized water to a concentration of $0.3 \mathrm{wt} \%$, followed by ultrasonic wave treatment to homogenize the dispersion. For the stress-strain test, the WPU freestanding films were cut into dumb-bell shaped samples with $20 \mathrm{~mm}$ length and $4 \mathrm{~mm}$ width. The tensile stress-strain test was performed on an Instron-1121 at an extension rate of $100 \mathrm{~mm} \mathrm{~min}^{-1}$ at $25^{\circ} \mathrm{C}$.

The stability of the CO2-WPU emulsion was evaluated by centrifugation of the sample at $3000 \mathrm{rpm}$ for $30 \mathrm{~min}$ on an ANKE TGL-10C system.

The zeta potential of the dispersions was measured on a Malvern-ZS90 system.

A FEI XL30 ESEM field emission scanning electron microscope (SEM) with an operating voltage of $15 \mathrm{kV}$ with chromium coating was used to observe the particle of WPU and the tensile fracture surfaces of the various WPU samples.

The $0.1 \mathrm{wt} \%$ emulsion was dyed with $2 \mathrm{wt} \%$ phosphotungstic acid and then subjected to JEOL JEM-2010 Transmission Electron Microscope (TEM) at an acceleration voltage of $200 \mathrm{kV}$.

X-ray diffraction (XRD) was carried out on Brucker D 8 Advance diffractometer with $\mathrm{Cu} \mathrm{K} \alpha$ radiation $(\lambda=1.542 \AA)$. The specimens were scanned from $10^{\circ}$ to $40^{\circ}$, with a step size of 0.02 and a scan speed of $6^{\circ} / \mathrm{min}$.

The tensile stress-strain test was performed on an Instron-1121 at an extension rate of $100 \mathrm{~mm} \mathrm{~min}^{-1}$ at $25{ }^{\circ} \mathrm{C}$ and $50 \%$ relative humidity. The average of three tests was reported for each specimen.

Adhesive strength (under peeling stresses) of the WPU dispersions was determined using the T-peel tests on the solvent-wiped, plasticized, ABS/polyurethane adhesive/solventwiped, plasticized, PVC joints. The ABS test samples had the dimensions of $25 \mathrm{~mm} \times 150$ $\mathrm{mm} \times 5 \mathrm{~mm}$. Prior to applying the PU dispersion, the ABS surface was wiped with methyl ethyl ketone, followed by solvent evaporation for $30 \mathrm{~min}$ in air. Subsequently, $0.45-0.92 \mathrm{~g}$ PU dispersions were applied by brush to the ABS strips for the joining. After water evaporation $\left(90 \mathrm{~min}\right.$ ), the adhesive film was rapidly heated at $80^{\circ} \mathrm{C}$ for $10 \mathrm{~s}$ under infrared radiation (reactivation process). The PVC strips were immediately placed in contact with the ABS test samples, and a pressure of $0.8 \mathrm{MPa}$ was applied for $10 \mathrm{~s}$ to achieve optimal bonding. The T-peel strength was measured $72 \mathrm{~h}$ after joint formation using Instron-1121 universal testing machine at a crosshead speed of $100 \mathrm{~mm} / \mathrm{min}$. The average of three tests was reported for each specimen.

Differential scanning calorimetry analysis was carried out using Perkin Elmer Thermal Analysis DSC-7. In total, $10 \mathrm{mg}$ samples were enclosed in the aluminum pans and were subsequently heated from 0 to $150{ }^{\circ} \mathrm{C}$ at a scanning rate of $10^{\circ} \mathrm{C} \mathrm{min}-1$ under a constant nitrogen flow.

The rectangular test bars were immersed into water for durations $(72 \mathrm{~h})$. The water absorption (A\%) of the samples was calculated according to Equation (1):

$$
\mathrm{A} \%=\left(\mathrm{W}_{1}-\mathrm{W}_{0}\right) / \mathrm{W}_{0} \times 100 \%
$$

where $W_{0}$ is the weight of the dry sample, and $W_{1}$ is the weight of the wet sample, measured immediately after the residual water was removed from the sample surface using filter paper. 
The static water contact angle of the WPU films was measured by the sessile drop method using JGW-360a contact angle goniometer (China) at $25^{\circ} \mathrm{C}$. The average of five tests was reported for each specimen.

\section{Results and Discussion}

FTIR analysis was carried out to investigate the chemical structure of WPUs and the spectra are displayed in Figure 1. The characteristic peaks of the free-NCO groups in the wavenumber range of $2250-2270 \mathrm{~cm}^{-1}$ were not found in WPUs spectra, which confirmed the completion of WPU synthesis reaction. Further, a new peak was observed at approximately $3350 \mathrm{~cm}^{-1}$, which corresponded to the $\mathrm{N}-\mathrm{H}$ stretching vibration. In addition, a combined peak was detected at $1532 \mathrm{~cm}^{-1}$, which indicated both N-H out-ofplane bending and C-N stretching. Besides, 2 peaks were observed at 2867 and $2950 \mathrm{~cm}^{-1}$, which were assigned to the $\mathrm{C}-\mathrm{H}$ stretching vibrations of urethane bonds. There were strong absorption peaks at $3350 \mathrm{~cm}^{-1}$ in the NH stretching region, which were attributed to the free NH stretching vibration as well as the hydrogen bonding between carbonyl groups and $\mathrm{NH}$. With an increase in $\mathrm{CO}$ content, the $\mathrm{NH}$ stretching peaks of $\mathrm{CO}_{0 \%}-\mathrm{WPU}, \mathrm{CO}_{2.50 \%}-$ WPU, $\mathrm{CO}_{5.04 \%}$-WPU, $\mathrm{CO}_{7.40 \%}$-WPU, and $\mathrm{CO}_{9.66 \%}$-WPU shifted from $3366 \mathrm{~cm}^{-1}$ to 3361 , 3353,3351 and $3349 \mathrm{~cm}^{-1}$ respectively. Castor oil molecules containing carbonyl groups tended to form hydrogen bonds with hydrogen atoms. The shift to lower frequencies indicated the formation of more hydrogen bonds.

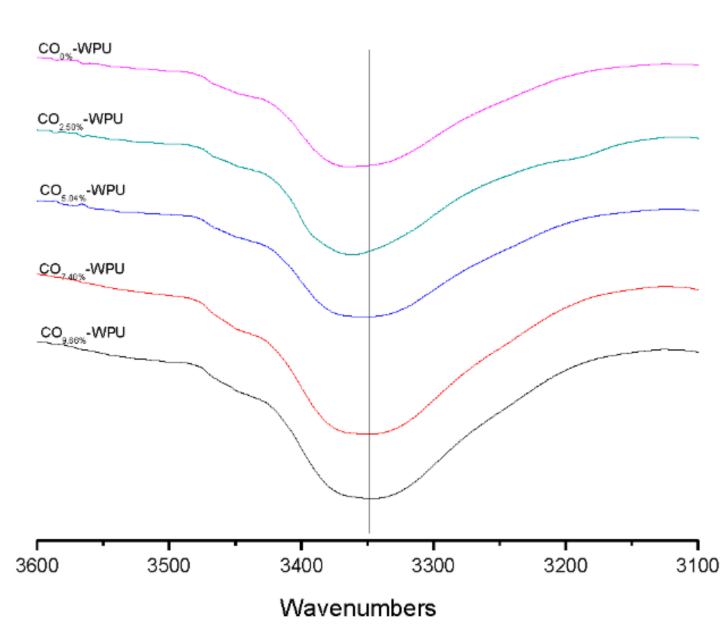

(a)

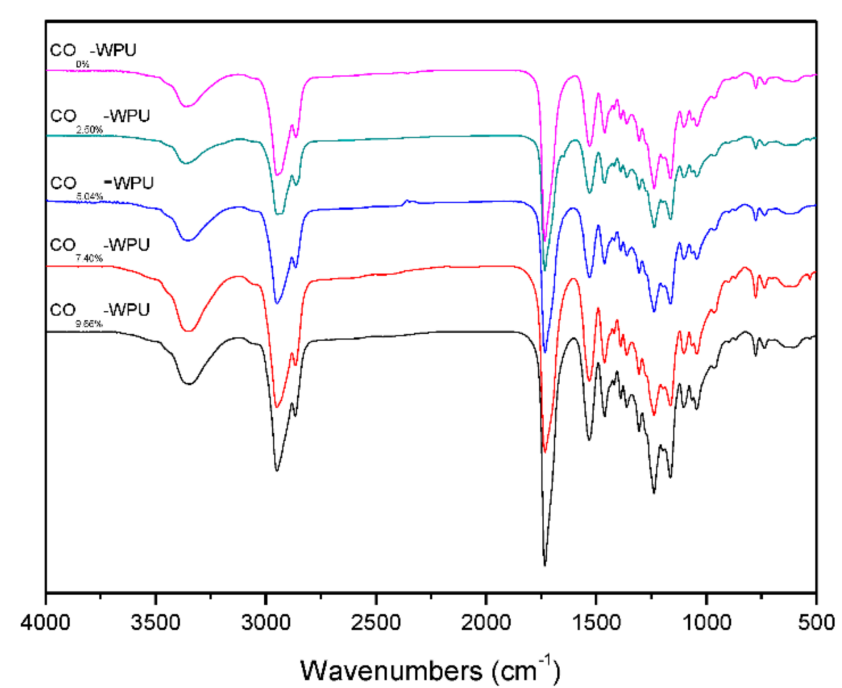

(b)

Figure 1. FT-IR spectra of WPUs. (a) in the wavenumber range of $3100-3600 \mathrm{~cm}^{-1}$; (b) in the wavenumber range of $\left.500-4000 \mathrm{~cm}^{-1}\right)$.

Figure 2 showed the particle size distributions of the WPUs with different content of $\mathrm{CO}$. As can be seen from Figure 2, $\mathrm{CO}_{0 \%}$-WPU sample exhibited unimodal PSD and the particle size was around 200 to $500 \mathrm{~nm}$. The polycaprolactone chain segments easily aggregate because of the good regularity so that most of the hydrophilic groups were embedded, resulting in the formation of larger particles during the water emulsification of the polymer. It can be found that $\mathrm{CO}_{2.50 \%}$-WPU sample exhibited smaller particle size and narrower PSD compared with $\mathrm{CO}_{0 \%}-\mathrm{WPU}$ although N-MDEA content (3.30 wt $\%$ ) that formed ionic centers by quaternization in polyurethane chains decreased. It was interesting to find that $\mathrm{CO}_{5.04 \%}$-WPU and $\mathrm{CO}_{7.40 \%}$-WPU exhibited bimodal particle size distribution while particle size became smaller. Unlike $\mathrm{CO}_{5.04 \%}-\mathrm{WPU}$ and $\mathrm{CO}_{7.40 \%}-\mathrm{WPU}$, $\mathrm{CO}_{9.66 \%}$-WPU exhibited unimodal PSD and the particle sizes were around 20 to $50 \mathrm{~nm}$. It can be shown that the particle size of WPU decreased with increasing CO content although the amount of hydrophilic moiety decreased. This can be explained by the fact that the 
addition of castor oil disrupted the aggregation of polycaprolactone segment, leaving the hydrophilic group exposed, which helped the polymer to form smaller emulsion ions in the process of the formation of latex particles. The micrographs of the representative regions of all samples were recorded at same magnification and demonstrated in Figure 3. The SEM micrographs of WPU films provided the data on flexibility and rigidity, surface morphology, and phase interaction. From the SEM images of the WPU films, a sophisticated surface morphology was found. What most attracts attention was that there were a number of free-standing small nanorods on the surface of $\mathrm{CO}_{0 \%}$-WPU film. In $\mathrm{CO}_{2.50 \%}$-WPU, the width of the trilateral and quadrangular cylinders ranged from $100 \mathrm{~nm}$ to $200 \mathrm{~nm}$. Many smaller spots can be seen on the films surface of $\mathrm{CO}_{5.04 \%}-\mathrm{WPU}$ and $\mathrm{CO}_{7.40 \%}$-WPU. The diameters of the well-dispersed dots on the surfaces of the two films were generally $<100 \mathrm{~nm}$. $\mathrm{CO}_{9.66 \%}-\mathrm{WPU}$ containing higher content of $\mathrm{CO}$ demonstrated a remarkable enhancement in homogeneity among particles, and it was more uniform. Figure 4 showed the TEM photographs of $\mathrm{CO}_{0 \%}-\mathrm{WPU}, \mathrm{CO}_{5.04 \%}-\mathrm{WPU}$, and $\mathrm{CO}_{9.66 \%}$-WPU. As can be seen in the TEM photographs, $\mathrm{CO}_{0 \%}-\mathrm{WPU}$ presented bimodal PSD and large particles were around $200 \mathrm{~nm}$ while small particles were around $50 \mathrm{~nm}$. When compared with the $\mathrm{CO}_{5.04 \%}-\mathrm{WPU}$ dispersion, exhibiting an average particle size of $50 \mathrm{~nm}$ diameter, a smaller particle size of $20 \mathrm{~nm}$ diameter was observed for $\mathrm{CO}_{9.66 \%}$-WPU with a larger $\mathrm{CO}$ content. These results were consistent with the particle size results, which further confirmed that the cationic hydrophilic group (N-MDEA) was located on the main chain of the polymer and embedded easily in the process of the formation of latex particles. $\mathrm{CO}$ in the samples, which could be related with restrictions in chain mobility and phase mixing increase, hindered the chain packing of polycaprolactone segment. Therefore, hydrophilic group was no longer the crucial influencing factor in determining particle size. The combination of $\mathrm{CO}$ exhibited a positive effect on the dispersion and stability properties of WPUs. It is found that the particle size and zeta potential of the WPUs influence the storage stability of the dispersion. As shown in Table 1, these WPUs demonstrate excellent storage stability. No obvious perception or stratification was observed when the WPUs were centrifuged at $3000 \mathrm{rpm}$ for $30 \mathrm{~min}$ and stored for 6 months at room temperature.

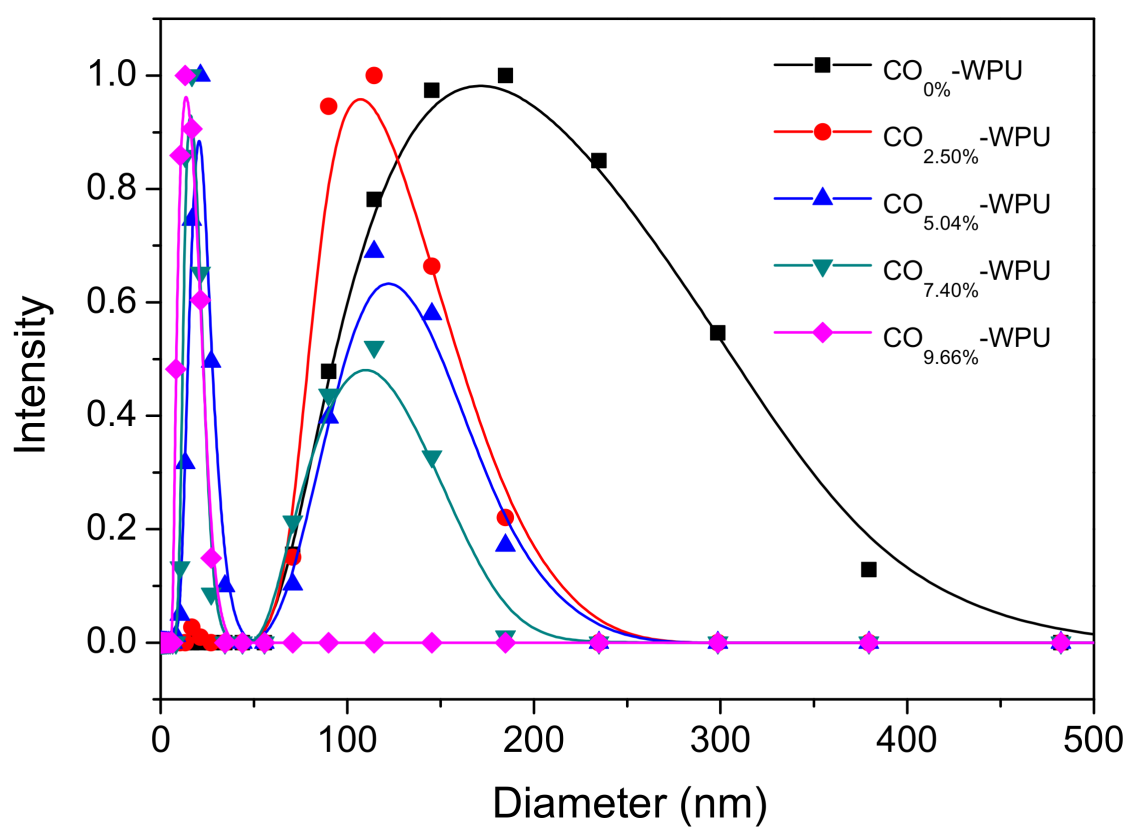

Figure 2. The particle size distribution of WPUs. 


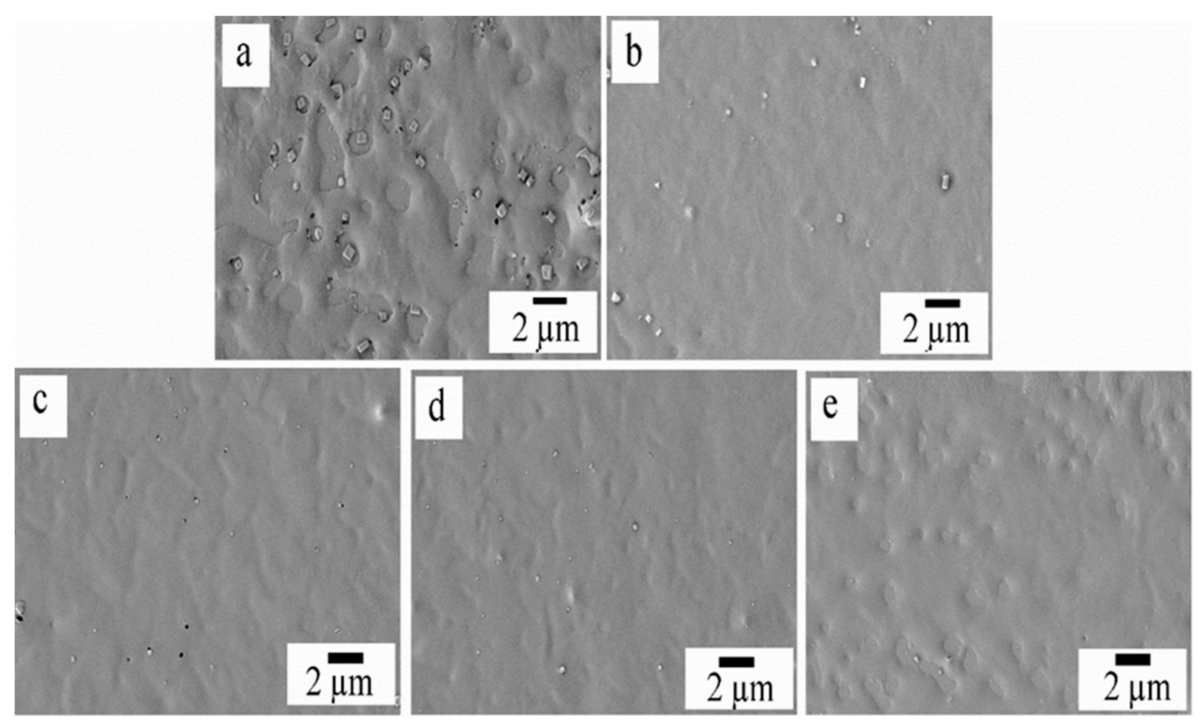

Figure 3. SEM micrographs of (a) $\mathrm{CO}_{0 \%}-\mathrm{WPU}$, (b) $\mathrm{CO}_{2.50 \%}-\mathrm{WPU}$, (c) $\mathrm{CO}_{5.04 \%}-\mathrm{WPU}$, (d) $\mathrm{CO}_{7.40 \%}-$ WPU and (e) $\mathrm{CO}_{9.66 \%}-\mathrm{WPU}$.
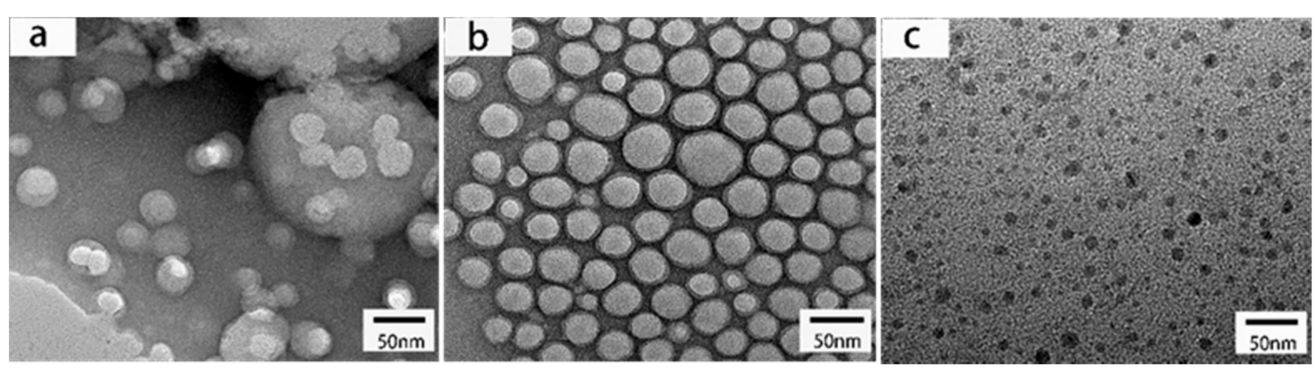

Figure 4. TEM micrographs of (a) $\mathrm{CO}_{0} \%-\mathrm{WPU}$, (b) $\mathrm{CO}_{5.04 \%}-\mathrm{WPU}$ and (c) $\mathrm{CO}_{9.66 \%}-\mathrm{WPU}$.

As shown in Figure 5, the WPUs exhibited two diffraction peaks attributing to the (200) and (110) planes of the PCL crystalline phase. There was no shift in the positions of these peaks and the peak intensity qualitatively declined on increasing castor oil concentrations, implying that the crystallinity decreased in the CO/WPU systems without affecting the crystal structure, and the crosslinking by castor oil restricted the chain packing of PCL crystals in the castor oil/PCL-based WPUs, thus leading to a reduction in crystallinity. In addition, the XRD diffractograms showed shoulder of the peak at 2 theta $=21^{\circ}$. The observed phenomenon could be attributed to the fact that the amorphous hard segment (CO) of the polymer was inductively produced to crystallize because of the formation of more hydrogen bonds.

To further explore the crystallinity of WPU films, the thermal properties of the films casted from the dispersion with various TMPM content were analyzed using DSC. According to Figure 6, all samples presented melting peak temperatures ranging from $45^{\circ} \mathrm{C}$ to $49^{\circ} \mathrm{C}$. This observed melting temperature could be attributed to the melting of pure PCL around $60^{\circ} \mathrm{C}$. Moreover, it was found that the peak melting temperatures of WPU films decreased with an increase in CO/PCL-OH molar ratio. As shown in Table 2, increasing the $\mathrm{CO}$ content led to a decrease in melting temperature and melting enthalpy. This result was consistent with the XRD result, which further confirmed that the crosslinking by castor oil restricted the PCL segment crystallization ability, enabling the formation of amorphous domains. 


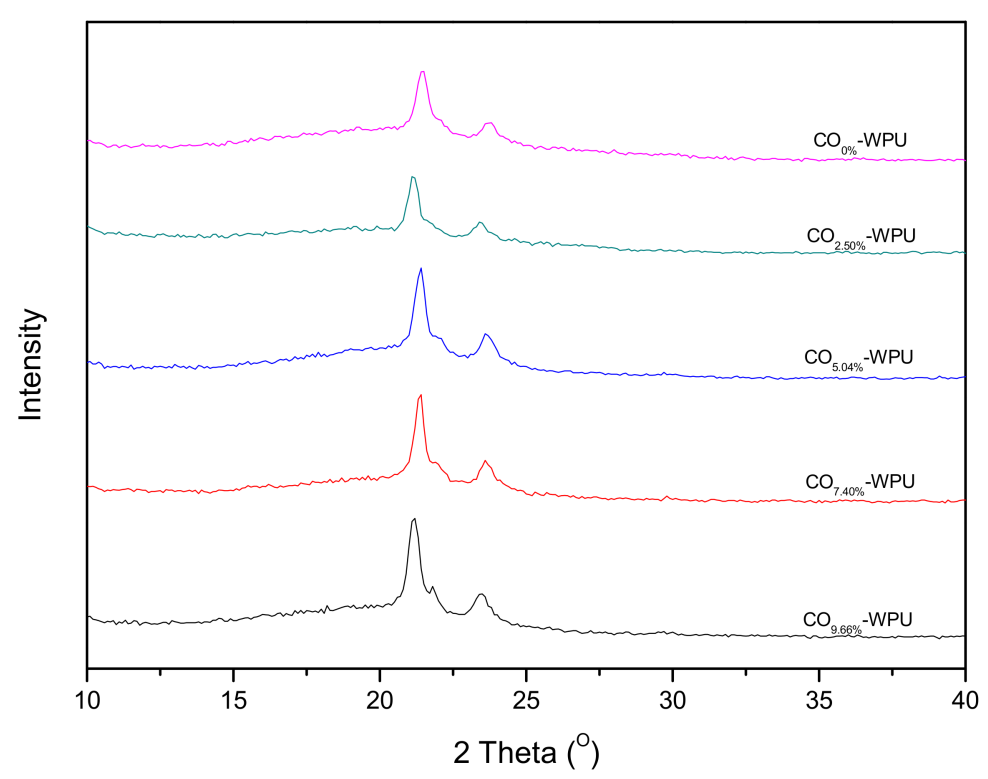

Figure 5. XRD-Ray diffraction pattern of WPU films.

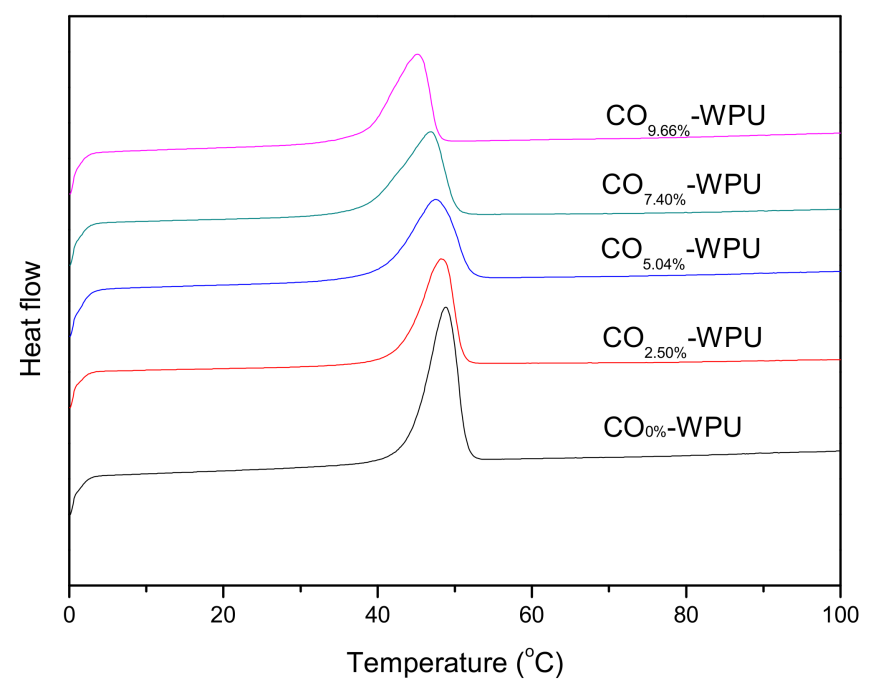

Figure 6. DSC thermograms of WPU films.

Table 2. Thermal properties of WPU films.

\begin{tabular}{cccccc}
\hline Sample & $\mathbf{C O}_{\mathbf{0} \%}-\mathbf{W P U}$ & $\mathbf{C O}_{\mathbf{2 . 5 0} \%}$-WPU & $\mathbf{C O}_{5.04 \%}-\mathbf{W P U}$ & $\mathbf{C O}_{\mathbf{7 . 4 0} \%}$-WPU & $\mathbf{C O}_{9.66 \%}-\mathbf{W P U}$ \\
\hline $\mathrm{Tm}\left({ }^{\circ} \mathrm{C}\right)$ & 48.8 & 48.2 & 47.5 & 46.8 & 45.2 \\
$\Delta \mathrm{H}(\mathrm{J} / \mathrm{g})$ & 47.7 & 44.6 & 42.2 & 39.1 & 38.0 \\
\hline
\end{tabular}

\subsection{Mechanical Performance of WPUs}

Previous research has shown that the crystallization behavior of semicrystalline polymer plays an essential role in regulating its mechanical properties, and the addition of second materials can influence its crystallinity [42]. The tensile stress-strain curves of WPU films were displayed in Figure 7, and the mechanical properties were presented in Table 2. The tensile strength of $\mathrm{CO}_{0 \%}-\mathrm{WPU}$ reached 24.1 MPa without any elongation at break (Table 3), which showed a typical brittle fracture. The tensile strength of $\mathrm{CO}_{2.50 \%}-\mathrm{WPU}$ reached 18.7 $\mathrm{MPa}$, which was lower than that of $\mathrm{CO}_{0 \%}-\mathrm{WPU}$. In addition, the elongation at break of $\mathrm{CO}_{2.50 \%}-\mathrm{WPU}$ was $110 \%$. As shown in Figure 7, with increasing $\mathrm{CO}$ content, the tensile strength of CO-WPUs decreased while the elongation at break increased. The addition of castor oil could lead to a marked improvement of elongation at break due to its 
crosslinking effect and a decrease in hard segment portion. For the castor oil/PCL-based WPUs, increasing the content of castor oil could remarkably enhance the cross-link density of WPU films. It can be described that more CO group may increase the toughness of the CO-WPU films and lead to a decrease in the rigidity.

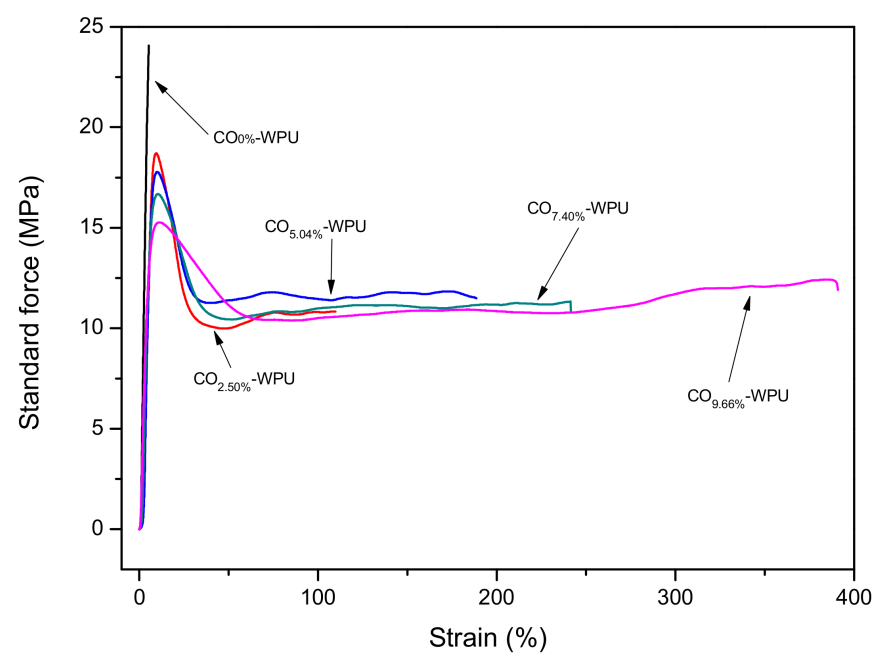

Figure 7. Tensile stress-strain curves of WPUs with different content of CO.

Table 3. Mechanical property of WPUs.

\begin{tabular}{cccccc}
\hline & $\mathbf{C O}_{\mathbf{0} \%}-\mathbf{W P U}$ & $\mathbf{C O}_{\mathbf{2 . 5 0} \%}-\mathbf{W P U}$ & $\mathbf{C O}_{\mathbf{5 . 0 4} \%}-\mathbf{W P U}$ & $\mathbf{C O}_{\mathbf{7 . 4 0} \%}-\mathbf{W P U}$ & $\mathbf{C O}_{\mathbf{9 . 6 6 \%}}-\mathbf{W P U}$ \\
\hline$\sigma_{\mathrm{m}}(\mathrm{MPa})$ & 24.1 & 18.7 & 17.8 & 17.0 & 15.3 \\
$\varepsilon_{\mathrm{b}}(\%)$ & 5.0 & 110 & 189 & 241. & 391 \\
$\sigma_{\mathrm{b}}(\mathrm{MPa})$ & - & 10.8 & 11.5 & 11.3 & 12.0 \\
\hline
\end{tabular}

A previous study demonstrated that the mechanical properties of WPUs were significantly associated with their morphology [44]. Thus, controlling the morphology is essential to obtain the desired properties in the WPUs. As far as we know, the crack of the materials may extend rapidly when a brittle failure occurs. Besides, the fracture surface appears to be quite smooth [45]. However, the surface of a ductile fracture may be misty and intricate due to the complex fracture mechanism and higher energy consumption. To understand the toughening effect of CO on PCL-WPU, the morphologies of the tensile fracture surfaces of various WPU samples were analyzed. As can be seen from Figure 8a, $\mathrm{CO}_{0}$-WPU demonstrated a common brittle fracture surface with shape of ridges, and the white crack of $\mathrm{CO}_{0 \%}$-WPU appeared to be large-scale ridge-like features. This suggests that the large crystalline dimension of PCL phase could result in the brittle failure at the macroscopic level, leading to a low elastic modulus. Upon addition of CO to WPU, with a decrease in crystalline dimension, the fracture surface presented increasing roughness. As CO increased, the fracture surfaces appeared more rugged with silk-like appearance, thus, indicating enhanced toughness. Figure $8 \mathrm{c}-\mathrm{e}$ showed very coarse fracture surfaces with the appearance of many rugged filaments called "dimples" [46], a characteristic of ductile rupture. From the above results, the addition of $\mathrm{CO}$ overcame brittleness effectively. In summary, on decreasing the crystalline dimension, the fracture mechanism in the WPU film transformed gradually from the brittle failure to the ductile fracture.

\subsection{T-Peel Strength Tests}

T-peel strength is regarded as the capability of an adhesive to join 2 surfaces together, which can be assessed by measuring the cohesive energy (cohesive in the adhesive bulk) and adhesive strength (adhesive to PVC). The crystallinity of soft segments and molar ratio of soft/hard segments are the main factors affecting both cohesive energy and adhesive strength. The T-peel strength of adhesive bonds of WPUs were determined (Table 1). The 
T-peel strength of $\mathrm{CO}_{0} \%$-WPU was very low because of the high crystallinity of the linear structure of PCL-WPU without any CO. As a result, the cohesive failure occurred when the bond with the substrate exceeded the internal strength of the adhesives, thus leading to a poor contact and adhesive strength. In contrast, the adhesive strengths was remarkably enhanced with increasing the CO content, which converted the WPU linear structure to crosslinked structure. The adhesive strength markedly enhanced at the maximum $\mathrm{CO}$ content, followed by a slight reduction. It can be seen that the $\mathrm{CO}_{7.40 \%}-\mathrm{WPU}$ had the highest adhesion strength, which indicated that better adhesion was achieved when higher cohesion and crosslinked structure were available. Nevertheless, a decrease in adhesion strength was observed with increasing $\mathrm{CO}$ content, leading to high tackiness and plasticization, and ultimately lowering the bond strength.

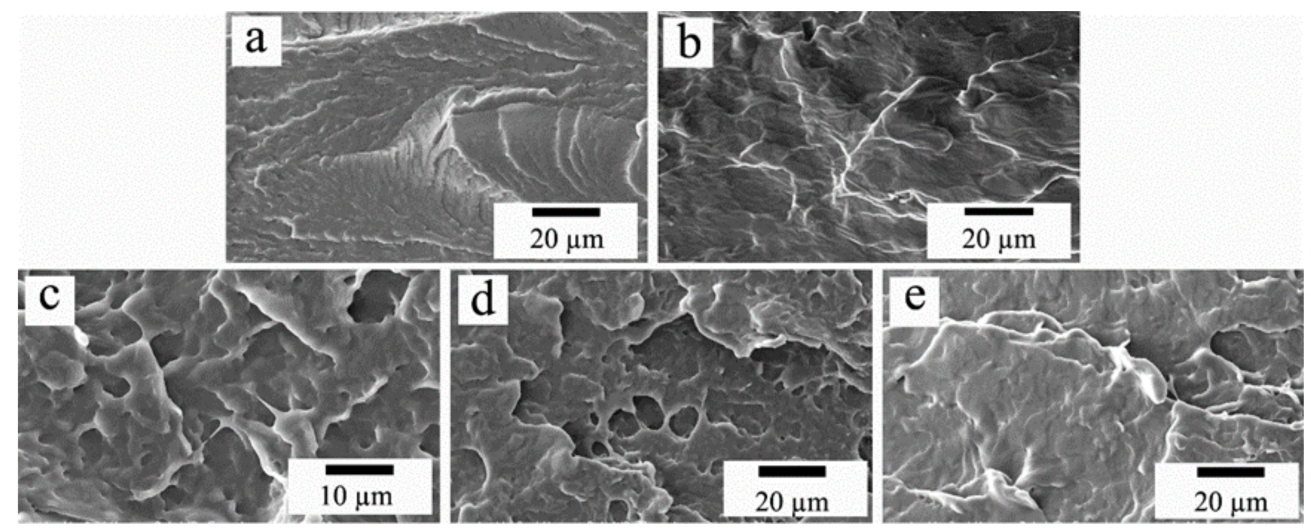

Figure 8. SEM micrographs of the tensile fracture surfaces of (a) $\mathrm{CO}_{0 \%}-\mathrm{WPU}$, (b) $\mathrm{CO}_{2.50 \%}-\mathrm{WPU}$, (c) $\mathrm{CO}_{5.04 \%}-\mathrm{WPU}$, (d) $\mathrm{CO}_{7.44 \%}-\mathrm{WPU}$, and (e) $\mathrm{CO}_{9.66 \%}-\mathrm{WPU}$.

Figure 9 presents the water contact angle and water absorption of the WPU films as a function of CO content. As observed, the water contact angle of the WPU films increased with the CO content, whereas the water absorption of the WPU films exhibited a decrease. As a result, the films could not be wetted easily. The water absorption of a polymer is an important parameter impacting its practical applications. On enhancing the CO content from 0 to $9.66 \mathrm{wt} \%$, the water absorption was observed to decrease from 23.2 to $13.9 \%$. It indicated that the $\mathrm{CO}$ acting as a crosslinker introduced in the PU backbone chain improved the water resistance of the WPU films.

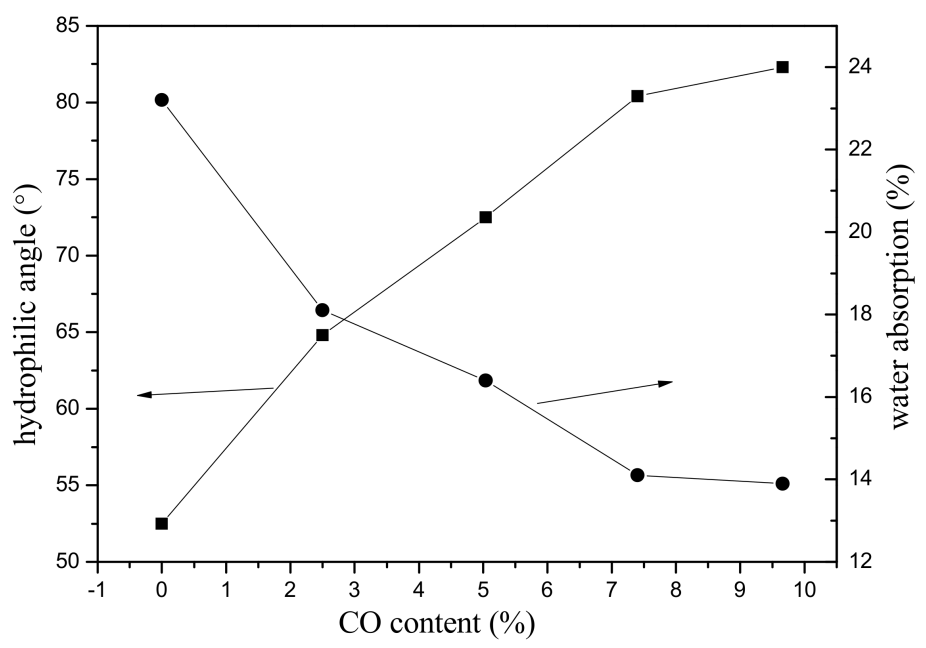

Figure 9. Hydrophilic angle and water absorption of WPU films as a function of TMPM content. 


\section{Conclusions}

Biobased, cationic WPUs were successfully constructed by varying the CO content, where stable aqueous dispersion was obtained even when N-MDEA loading was as low as $3.16 \mathrm{wt} \%$. A bonus of this low hydrophilic moiety was the excellent adhesive strength, whose T-peel strength could reach $36.8 \mathrm{~N} / 25 \mathrm{~mm}$, about $114 \%$ higher than that of WPU $(17.2 \mathrm{~N} / 25 \mathrm{~mm})$ without any $\mathrm{CO}$ content. The elongation at break of $\mathrm{CO}_{7.40 \%}-\mathrm{WPU}$ was $391 \%$. The mechanical performance, film-forming property, flexibility, and adhesion of the cationic WPU films could be tuned by adjusting the CO loading. WPUs containing higher content of $\mathrm{CO}$ demonstrated a remarkable enhancement in homogeneity among particles and $\mathrm{CO}_{7.40 \%}$-WPU had the highest adhesion strength. The combination of $\mathrm{CO}$ has a positive effect on the dispersion and stability properties of WPUs. On increasing the CO content, the tensile strength of WPU films was observed to decrease, and the elongation at break increased owing to the average hydroxyl functionality of 2.7 chains introduced in the PU backbone chain, along with a reduction in the content of the hard segments. In addition, the incorporation of $\mathrm{CO}$ hindered the PCL chain packing, leading to a reduced crystallinity in the WPU films. Overall, using $\mathrm{CO}$ as an addition of second material improved the mechanical properties, wettability, water resistance and adhesive strength of PCL-WPUs. The experimental findings indicated that the CO-modified PCL-WPUs displayed excellent film-forming property, flexibility, and adhesion. Collectively, this study provides a novel strategy to synthesize eco-friendly, high performance, biodegradable polymers for diverse applications. Further detailed investigations on the synthesis and properties of the CO-modified PCL-WPUs are underway.

Author Contributions: Conceptualization, Y.L.; methodology, S.C. and S.Z.; software, M.L.; R.L. and W.X.; validation, J.S.; formal analysis, J.S.; investigation, J.S.; resources, J.S.; data curation, Y.L.; writing—original draft preparation, Y.L.; writing—review and editing, Y.L.; supervision, J.S.; project administration, J.S. All authors have read and agreed to the published version of the manuscript.

Funding: This study was supported by the National Natural Science Foundation of China (31971582).

Institutional Review Board Statement: Not applicable.

Informed Consent Statement: Not applicable.

Data Availability Statement: Not applicable.

Conflicts of Interest: The authors declare no conflict of interest.

\section{References}

1. Guo, J.H.; Liu, Y.C.; Chai, T.; Jing, S.M.; Ma, H.; Qin, N.; Zhou, H.; Yan, T.; He, W.M. Synthesis and properties of a nano-silica modified environmentally friendly polyurethane adhesive. RSC Adv. 2015, 5, 44990-44997. [CrossRef]

2. Kim, E.H.; Myoung, S.W.; Jung, Y.G.; Paik, U. Polyhedral oligomeric silsesquioxane-reinforced polyurethane acrylate. Prog. Org. Coat. 2009, 64, 205-209. [CrossRef]

3. Valcic, M.D.; Cakic, S.M.; Ristic, I.S.; Cakic, J.D.; Cvetinov, M.J.; Janos, C.J. Polycaprolactone-based biodegradable acrylated polyurethanes: Influence of nanosilica amount on functional properties. Int. J. Adhes. Adhes. 2021, 104. [CrossRef]

4. Jeon, H.T.; Jang, M.K.; Kim, B.K.; Kim, K.H. Synthesis and characterizations of waterborne polyurethane-silica hybrids using sol-gel process. Colloid Surf. A 2007, 302, 559-567. [CrossRef]

5. Xu, W.; Zhao, W.J.; Hao, L.F.; Wang, S.; Pei, M.M.; Wang, X.C. Synthesis and characterization of novel fluoroalkyl-terminated hyperbranched polyurethane latex. Appl. Surf. Sci. 2018, 436, 1104-1112. [CrossRef]

6. Madbouly, S.A. Waterborne Polyurethane Dispersions and Thin Films: Biodegradation and Antimicrobial Behaviors. Molecules 2021, 26, 961. [CrossRef]

7. Sundar, S.; Vijayalakshmi, N.; Gupta, S.; Rajaram, R.; Radhakrishnan, G. Aqueous dispersions of polyurethane-polyvinyl pyridine cationomers and their application as binder in base coat for leather finishing. Prog. Org. Coat. 2006, 56, 178-184. [CrossRef]

8. Zhang, M.S.; Hemp, S.T.; Zhang, M.Q.; Allen, M.H.; Carmean, R.N.; Moore, R.B.; Long, T.E. Water-dispersible cationic polyurethanes containing pendant trialkylphosphoniums. Polym. Chem. 2014, 5, 3795-3803. [CrossRef]

9. Dong, C.H.; Xin, W.; Luo, Y.J. Synthesis and application of a cationic waterborne polyurethane fixative using quaternary ammonium diol as a chain extender. RSC Adv. 2018, 8, 42041-42048. [CrossRef]

10. Li, M.; Liu, F.; Li, Y.; Qiang, X.H. Synthesis of stable cationic waterborne polyurethane with a high solid content: Insight from simulation to experiment. RSC Adv. 2017, 7, 13312-13324. [CrossRef] 
11. Krol, P.; Krol, B. Polyurethane cationomers synthesised with 4, $4^{\prime}$-methylenebis(phenyl isocyanate), polyoxyethylene glycol and N-methyl diethanolamine. Colloid Polym. Sci. 2008, 286, 1111-1122. [CrossRef]

12. Xin, H.; Shen, Y.D.; Li, X.R. Novel cationic polyurethane-fluorinated acrylic hybrid latexes: Synthesis, characterization and properties. Colloid Surf. A 2011, 384, 205-211. [CrossRef]

13. Mohanty, S.; Krishnamurti, N. Synthesis and characterization of aqueous cationomeric polyurethanes and their use as adhesives J. Appl. Polym. Sci. 1996, 62, 1993-2003. [CrossRef]

14. Chen, K.L.; Gou, W.W.; Wang, X.M.; Zeng, C.J.; Ge, F.Q.; Dong, Z.J.; Wang, C.X. UV-Cured Fluoride-Free Polyurethane Functionalized Textile with $\mathrm{pH}$-Induced Switchable Superhydrophobicity and Underwater Superoleophobicity for Controllable Oil/Water Separation. ACS Sustain. Chem. Eng. 2018, 6, 16616-16628. [CrossRef]

15. Wu, D.M.; Qiu, F.X.; Xu, H.P.; Zhang, J.L.; Yang, D.Y. Preparation, Characterization, and Properties of Environmentally Friendly Waterborne Poly(urethane acrylate)/Silica Hybrids. J. Appl. Polym. Sci. 2011, 119, 1683-1695. [CrossRef]

16. Fang, H.G.; Wang, H.L.; Sun, J.; Wei, H.B.; Ding, Y.S. Tailoring elastomeric properties of waterborne polyurethane by incorporation of polymethyl methacrylate with nanostructural heterogeneity. RSC Adv. 2016, 6, 13589-13599. [CrossRef]

17. Fei, G.Q.; Zhu, K.; Wang, H.H.; Shen, Y.D.; Zou, J.; Lan, J. Morphology, Dynamic Rheology, and Cohesive Properties of EpoxyModified Polyurethane-Acrylate Microemulsions Prepared by In Situ Surfactant-Free Polymerization. J. Appl. Polym. Sci. 2014, 131. [CrossRef]

18. Chen, G.D.; Zhou, S.X.; Gu, G.X.; Wu, L.M. Acrylic-based polyurethane/silica hybrids prepared by acid-catalyzed sol-gel process: Structure and mechanical properties. Macromol. Chem. Phys. 2005, 206, 885-892. [CrossRef]

19. Cakic, S.M.; Ristic, I.S.; M-Cincovic, M.; Stojiljkovic, D.T.; B-Simendic, J. Preparation and characterization of waterborne polyurethane/silica hybrid dispersions from castor oil polyols obtained by glycolysis poly (ethylene terephthalate) waste. Int. J. Adhes. Adhes. 2016, 70, 329-341. [CrossRef]

20. Pellis, A.; Malinconico, M.; Guarneri, A.; Gardossi, L. Renewable polymers and plastics: Performance beyond the green. New Biotechnol. 2021, 60, 146-158. [CrossRef]

21. Wang, Z.K.; Ganewatta, M.S.; Tang, C.B. Sustainable polymers from biomass: Bridging chemistry with materials and processing. Prog. Polym. Sci. 2020, 101. [CrossRef]

22. Gandini, A.; Lacerda, T.M. From monomers to polymers from renewable resources: Recent advances. Prog. Polym. Sci. 2015, 48. [CrossRef]

23. Kamairudin, N.; Hoong, S.S.; Abdullah, L.C.; Ariffin, H.; Biak, D.R.A. Optimisation of Epoxide Ring-Opening Reaction for the Synthesis of Bio-Polyol from Palm Oil Derivative Using Response Surface Methodology. Molecules 2021, 26, 648. [CrossRef] [PubMed]

24. Hong, M.; Chen, E.Y.X. Chemically recyclable polymers: A circular economy approach to sustainability. Green Chem. 2017, 19, 3692-3706. [CrossRef]

25. Miller, S.A. Sustainable polymers: Replacing polymers derived from fossil fuels. Polym. Chem. 2014, 5, 3117-3118. [CrossRef]

26. Coates, G.W.; Hillmyer, M.A. A Virtual Issue of Macromolecules: "Polymers from Renewable Resources". Macromolecules 2009, 42, 7987-7989. [CrossRef]

27. Gandini, A.; Lacerda, T.M.; Carvalho, A.J.F.; Trovatti, E. Progress of Polymers from Renewable Resources: Furans, Vegetable Oils, and Polysaccharides. Chem. Rev. 2016, 116, 1637-1669. [CrossRef]

28. Lu, Y.S.; Larock, R.C. Aqueous Cationic Polyurethane Dispersions from Vegetable Oils. ChemSuschem 2010, 3, 329-333. [CrossRef]

29. Zhang, Y.; Zhang, W.B.; Deng, H.H.; Zhang, W.H.; Kang, J.; Zhang, C.Q. Enhanced Mechanical Properties and Functional Performances of Cationic Waterborne Polyurethanes Enabled by Different Natural Phenolic Acids. ACS Sustain. Chem. Eng. 2020, 8, 17447-17457. [CrossRef]

30. Gurunathan, T.; Mohanty, S.; Nayak, S.K. Effect of reactive organoclay on physicochemical properties of vegetable oil-based waterborne polyurethane nanocomposites. RSC Adv. 2015, 5, 11524-11533. [CrossRef]

31. Cakic, S.M.; Valcic, M.D.; Ristic, I.S.; Radusin, T.; Cvetinov, M.J.; Budinski-Simendic, J. Waterborne polyurethane-silica nanocomposite adhesives based on castor oil-recycled polyols: Effects of (3-aminopropyl)triethoxysilane (APTES) content on properties. Int. J. Adhes. Adhes. 2019, 90, 22-31. [CrossRef]

32. Gutierrez, T.J.; Mendieta, J.R.; Ortega-Toro, R. In-depth study from gluten/PCL-based food packaging films obtained under reactive extrusion conditions using chrome octanoate as a potential food grade catalyst. Food Hydrocolloid 2021, $111,106255$. [CrossRef]

33. Moussaif, N.; Irusta, S.; Yague, C.; Arruebo, M.; Meier, J.G.; Crespo, C.; Jimenez, M.A.; Santamaria, J. Mechanically reinforced biodegradable nanocomposites. A facile synthesis based on PEGylated silica nanoparticles. Polymer 2010, 51, 6132-6139. [CrossRef]

34. Terzopoulou, Z.; Baciu, D.; Gounari, E.; Steriotis, T.; Charalambopoulou, G.; Tzetzis, D.; Bikiaris, D. Composite Membranes of Poly(epsilon-caprolactone) with Bisphosphonate-Loaded Bioactive Glasses for Potential Bone Tissue Engineering Applications. Molecules 2019, 24, 3067. [CrossRef]

35. Li, J.W.; Cheng, Y.H.; Lee, H.T.; Tsen, W.C.; Chiu, C.W.; Suen, M.C. Properties and degradation of castor oil-based fluoridated biopolyurethanes with different lengths of fluorinated segments. RSC Adv. 2019, 9, 31133-31149. [CrossRef] 
36. Cernadas, T.; Morgado, S.; Alves, P.; Goncalves, F.A.M.M.; Correia, T.R.; Correia, I.J.; Ferreira, P. Preparation of functionalized poly(caprolactone diol)/castor oils blends to be applied as photocrosslinkable tissue adhesives. J. Appl. Polym. Sci. 2020, 137. [CrossRef]

37. Field, J.; Haycock, J.W.; Boissonade, F.M.; Claeyssens, F. A Tuneable, Photocurable, Poly(Caprolactone)-Based Resin for Tissue Engineering-Synthesis, Characterisation and Use in Stereolithography. Molecules 2021, 26, 1199. [CrossRef]

38. Hailemeskel, B.Z.; Hsu, W.H.; Addisu, K.D.; Andrgie, A.T.; Chou, H.Y.; Lai, J.Y.; Tsai, H.C. Diselenide linkage containing triblock copolymer nanoparticles based on Bi(methoxyl poly(ethylene glycol))-poly(epsilon-carprolactone): Selective intracellular drug delivery in cancer cells. Mater. Sci. Eng. C Mater. 2019, 103. [CrossRef]

39. Kwak, Y.S.; Kim, H.D. Preparation and properties of waterborne polyurethanes based on triblock glycol (CL)(4.5)-PTMG-(CL)(4.5) for water vapor permeable coatings: Effect of soft segment content. Fiber Polym. 2002, 3, 153-158. [CrossRef]

40. Zhou, X.; Li, Y.; Fang, C.Q.; Li, S.J.; Cheng, Y.L.; Lei, W.Q.; Meng, X.J. Recent Advances in Synthesis of Waterborne Polyurethane and Their Application in Water-based Ink: A Review. J. Mater. Sci. Technol. 2015, 31, 708-722. [CrossRef]

41. Wang, G.; Ma, G.Z.; Hou, C.Y.; Guan, T.T.; Ling, L.X.; Wang, B.J. Preparation and Properties of Waterborne Polyurethane/Nanosilica Composites: A Diol as Extender with Triethoxysilane Group. J. Appl. Polym. Sci. 2014, 131. [CrossRef]

42. Wang, J.; Ye, L. Structure and properties of polyvinyl alcohol/polyurethane blends. Compos. Part B Eng. 2015, 69, 389-396. [CrossRef]

43. Barni, A.; Levi, M. Aqueous polyurethane dispersions: A comparative study of polymerization processes. J. Appl. Polym. Sci. 2003, 88, 716-723. [CrossRef]

44. Wu, H.; Wan, Y.; Cao, X.Y.; Wu, Q. Interlocked chitosan/poly(DL-lactide) blends. Mater. Lett. 2008, 62, 330-334. [CrossRef]

45. Feng, F.; Ye, L. Morphologies and Mechanical Properties of Polylactide/Thermoplastic Polyurethane Elastomer Blends. J. Appl. Polym. Sci. 2011, 119, 2778-2783. [CrossRef]

46. Liu, Y.Y.; Sun, H.; Tan, H.F.; Du, X.W. Modified Shape Memory Epoxy Resin Composites by Blending Activity Polyurethane. J. Appl. Polym. Sci. 2013, 127, 3152-3158. [CrossRef] 